\title{
Frequency Selective Non-Linear Blending to Improve Image Quality in Liver CT
}

\section{Frequenzselektives, nichtlineares Fenstern zu Steigerung der Bildqualität in der Computertomografie der Leber}

Authors

Affiliations
M. N. Bongers ${ }^{1}$, G. Bier ${ }^{1}$, C. Kloth ${ }^{1}$, C. Schabel' ${ }^{1}$, J. Fritz² ${ }^{2}$ K. Nikolaou' ${ }^{1}$, M. Horger ${ }^{1}$

Department of Diagnostic and Interventional Radiology, University Hospital of Tübingen, Germany

Russell H. Morgan Department of Radiology and Radiological Science, Johns Hopkins University School of Medicine, Baltimore, United States
Key words

- non-linear blending

- poor contrast

- liver vasculature

- objective analysis

- subjective analysis

- computed tomography

received 27.7.2016 accepted $\quad 28.8 .2016$

\section{Bibliography}

Dol http://dx.doi.org/

10.1055/s-0042-116440

Published online: 2016

Fortschr Röntgenstr 2016; 188:

1163-1168 @ Georg Thieme

Verlag KG Stuttgart · New York .

ISSN 1438-9029

\section{Correspondence \\ Dr. Malte Bongers}

Department of Diagnostic and Interventional Radiology,

University Hospital of Tübingen Hoppe-Seyler-Straße 3

72076 Tübingen

Germany

Tel.: ++ 49/7071/2986677

Fax: ++49/70 71/294638

malte.bongers@med.uni-

tuebingen.de

\section{Zusammenfassung \\ $\nabla$}

Ziel: Ziel der Studie war es herauszufinden welche Effekte durch einen neuartigen, frequenzselektiven Algorithmus der nichtlinearen Fensterung (NLF) zur Steigerung des Bildkontrastes bei primär gering kontrastierten CT-Bildern erzielt werden können. Material und Methoden: Diese retrospektive Studie wurde von der lokalen Ethikkommission begutachtet und genehmigt. Als Modell für eine geringe Gefäßkontrastierung wurden CT-Spätphasen der Leber von 25 Patienten (60\% weiblich, mittleres Alter $65 \pm 16$ Jahre) ausgewählt. Die optimalen Post-Processing-Einstellungen zur Steigerung der hepatischen Gefäßkontrastierung wurden subjektiv ermittelt. Es wurde das Signal-zu-Rausch-Verhältnis (SNR) und Kontrast-zu-Rausch-Verhältnis (CNR) der Lebergefäße sowie das SNR des Leberparenchyms mittels ROI-Analyse bestimmt und zwischen den Standard- und NLF-Bildern verglichen. Die subjektive Bildqualität wurde unter Verwendung von Likert-Skalen von zwei unabhängigen Radiologen bewertet.

Ergebnisse: Die optimalen Post-Processing-Einstellungen zur Darstellung der Lebergefäße waren ein Fensterzentrum von 115 HU und eine Fensterweite von $25 \mathrm{HU}$ bei einer Steigung von 5. Das Bildrauschen zeigte keinen signifikanten Unterschied zwischen den Standard- und NLF-Bildern. Das CNR zwischen den Lebergefäßen und dem Leberparenchym konnte sowohl bzgl. der Lebervenen $\left(\mathrm{CNR}_{\text {Standard }}\right.$ $\left.1,62 \pm 1,10, \mathrm{CNR}_{\mathrm{NLF}} 3,6 \pm 2,94, \mathrm{p}=0,0002\right)$ als auch der Pfortader $\left(\mathrm{CNR}_{\text {Standard }} 1,31 \pm 0,85, \mathrm{CNR}_{\mathrm{NLF}} 2,42 \pm\right.$ $3,03, p=0,046)$ signifikant gesteigert werden. In den NLF-Bildern konnte ein signifikant höheres SNR des Leberparenchyms als in den StandardBildern festgestellt werden $\left(\mathrm{SNR}_{\mathrm{NLF}} 11,26 \pm 3,16\right.$, $\mathrm{SNR}_{\text {Standard }} 8,85 \pm 2,27, \mathrm{p}=0,008$ ). Die Gesamtbildqualität (BQ) und Beurteilbarkeit der Lebergefäße (BLG) war in den NLF-Bildern signifikant höher als

\section{Abstract \\ $\nabla$}

Purpose: To evaluate the effects of a new frequency selective non-linear blending (NLB) algorithm on the contrast resolution of liver CT with low intravascular concentration of iodine contrast. Materials and Methods: Our local ethics committee approved this retrospective study. The informed consent requirement was waived. CT exams of 25 patients ( $60 \%$ female, mean age: $65 \pm 16$ years of age) with late phase CT scans of the liver were included as a model for poor intrahepatic vascular contrast enhancement. Optimal post-processing settings to enhance the contrast of hepatic vessels were determined. Outcome variables included signal-to-noise (SNR) and contrast-to-noise ratios (CNR) of hepatic vessels and SNR of liver parenchyma of standard and post-processed images. Image quality was quantified by two independent readers using Likert scales.

Results: The post-processing settings for the visualization of hepatic vasculature were optimal at a center of $115 \mathrm{HU}$, delta of $25 \mathrm{HU}$, and slope of 5 . Image noise was statistically indifferent between standard and post-processed images. The CNR between the hepatic vasculature (HV) and liver parenchyma could be significantly increased for liver veins $\left(\mathrm{CNR}_{\text {Standard }} 1.62 \pm 1.10, \mathrm{CNR}_{\mathrm{NLB}} 3.6 \pm 2.94\right.$, $\mathrm{p}=0.0002)$ and portal veins $\left(\mathrm{CNR}_{\text {Standard }} 1.31 \pm 0.85\right.$, $\mathrm{CNR}_{\mathrm{NLB}} 2.42 \pm 3.03, \mathrm{p}=0.046$ ). The SNR of liver parenchyma was significantly higher on post-processed images $\left(\mathrm{SNR}_{\mathrm{NLB}} 11.26 \pm 3.16, \mathrm{SNR}_{\text {Standard }} 8.85 \pm\right.$ $2.27, \mathrm{p}=0.008$ ). The overall image quality and depiction of HV were significantly higher on postprocessed images $\left(\mathrm{NLB}_{\mathrm{DHV}}: 4[3-4.75], \mathrm{S}_{\text {tandardDHV }}\right.$ : 2 [1.3-2.5], $\mathrm{p}=<0.0001$; ${ }_{\mathrm{NLBIQ}}: 4$ [4-4], StandardIQ: $2[2-3], \mathrm{p}=<0.0001)$.

Conclusion: The use of a frequency selective nonlinear blending algorithm increases the contrast resolution of liver CT and can improve the visibi- 
in den Standard-Bildern $\left(\mathrm{BLG}_{\mathrm{NLF}}: 4\right.$ [3 - 4,75], BLG $\mathrm{Btandard}_{\text {S }}$ [ [1,3 - 2,5], $\mathrm{p}=<0,0001 ; \mathrm{IQ}_{\mathrm{NLF}}: 4[4-4], \mathrm{IQ}_{\text {Standard}}: 2$ [2 -3], p = <0,0001).

Schlussfolgerung: Mittels frequenzselektiven, nichtlinearen Fensterung lässt sich der Kontrast in der CT der Leber steigern und die Beurteilbarkeit der Lebergefäße in gering kontrastierten CTBildern signifikant verbessern.

Kernaussagen:

Der neuartige Post-Processing-Algorithmus der frequenzselektiven, nichtlinearen Fensterung lässt sich in der kontrastangehobenen CT der Leber einsetzen.

- Durch die optimalen Post-Processing-Einstellungen ist eine signifikante Steigerung des Kontrastes der Lebergefäße ohne Beeinflussung des Bildrauschens zu erzielen.

- Insbesondere bei primär gering kontrastierten CT-Bildern lässt sich durch den neuartigen Algorithmus die Bildqualität signifikant verbessern. lity of the hepatic vasculature in the setting of a low contrast ratio between vessels and the parenchyma.

Key Points:

- Using the new frequency selective non-linear blending algorithm is feasible in contrast-enhanced liver CT.

$>$ Optimal post-processing settings make it possible to significantly increase the contrast resolution of liver CT without affecting image noise.

Especially in low contrast CT images, the novel algorithm is capable of significantly increasing image quality.

Citation Format:

- Bongers MN, Bier G, Kloth C et al. Frequency Selective Non-Linear Blending to Improve Image Quality in Liver CT. Fortschr Röntgenstr 2016; 188: 1163-1168

\section{Introduction}

$\nabla$

In CT imaging of the liver, reliable visualization of hepatic vasculature is essential. However, even with the use of a state-of-theart multi-slice CT technique, suboptimal contrast opacification occurs $[1,2]$. Available techniques to improve the opacification of the liver vasculature include mono-energetic extrapolation of dual-energy CT (DECT) datasets near the k-edge of iodine [3-5] and single energy data acquisition with low tube voltages of 70 $80 \mathrm{kV}[6,7]$. However, in cases in which these technologies are not available, post-processing methods that can improve the contrast resolution between iodine contrast and liver parenchyma may be helpful.

Selective windowing of CT images (blending) is commonly used to enhance the display of anatomic structures and may be used to improve the contrast resolution of contrast-opacified hepatic vessels and parenchyma. However, early efforts with one blending setting resulted in reduced detectability of low-contrast liver lesions [8]. As standard windowing techniques usually affect the entire dynamic range of pixel values equally, different standard blending settings [9] and empiric nonlinear blending settings were explored [10], but have not transitioned into clinical practice. We explored a new non-linear blending algorithm prototype that is based on a frequency split technique in order to selectively augment Hounsfield Units (HU) in a predefined range.

The aim of this study was to evaluate the usefulness of frequency selective non-linear blending for improving the quality of contrast enhancement CT images of the liver.

\section{Materials and methods}

Our local ethics committee approved this retrospective study. The informed consent requirement was waived.

\section{Study cohort}

The study cohort consisted of patients that underwent standard of care CT of the liver. The inclusion criteria included adult age and the presence of an equilibrium phase (acquired at $148-319 \mathrm{~s}$ after contrast media application, mean: 199 s) as a model of a low contrast situation, such as an erroneously timed portal venous phase. 25 patients ( $\bullet$ Table 1 ) were identified in our radiology information system.

\section{CT scanning protocol}

All CT scans were acquired using a second-generation dual-source CT scanner (SOMATOM Definition Flash, Siemens Healthcare, Germany). The scanning parameters for the equilibrium phase included a tube voltage of $120 \mathrm{kV}$, automated tube current modulation with a reference effective tube current of $180 \mathrm{mAs}$, collimation $2 \times 0.6 \times 64$, and a pitch of 0.6 . CT data were obtained after administration of a body weight-adapted amount of contrast agent (Imeron 400 , Bracco, Germany) and a saline flush $(40 \mathrm{ml})$ through an antecubital vein catheter at a flow rate of $2.2 \mathrm{ml} / \mathrm{s}$ using a dual-syringe injector (CT Stellant, Medrad, Indianola, Pennsylvania, USA).

\section{CT images post-processing}

Post-processing was performed with standard $120 \mathrm{kV}$ images using a non-linear blending algorithm prototype (Best Contrast, Siemens Healthcare, Erlangen, Germany) that allows for blending in the image space. Using mathematical methods, a CT image I can be divided into two complementary image datasets. At first, a discrete Fourier transform is applied to convert the intensity values of pixels into a frequency spectrum. Second, a high pass filter composes the first dataset $\mathrm{I}_{\text {high }}$, containing sharp details and the major part of the image noise. The second dataset $\mathrm{I}_{\text {low }}$, resulting from a low pass filter, shows the smooth content of the image but only minimal noise. At this point, by adding up both datasets $\mathrm{I}_{\text {low }}$ and $\mathrm{I}_{\text {high}}$, the original image I can be restored in a lossless manner. This non-linear blending algorithm prototype selectively increases the contrast in the $\mathrm{I}_{\text {low }}$ dataset by spreading a preselected range of HU values, resulting in a new dataset $\mathrm{I}_{\text {lowEnh. }}$. The spreading is performed using a non-linear function, whereas the slope

Table 1 Patient demographics and imaging parameters of the 25 subjects included in the analysis.

Tab. 1 Patientencharakteristika und Bildakquisitionsparameter der $25 \mathrm{~Pa}$ tienten dieser Studie.

\begin{tabular}{|ll|}
\hline parameter & value \\
\hline gender & \\
\hline - women & $15(60 \%)$ \\
\hline - men & $10(40 \%)$ \\
\hline age $[\mathrm{y}]$ & $65.3 \pm 16.2($ Range: $23-88)$ \\
\hline BMl $\left[\mathrm{kg} / \mathrm{m}^{2}\right]$ & $24.2 \pm 4.3($ Range: $16.2-35.6)$ \\
\hline dose-length product $[\mathrm{mGy} \cdot \mathrm{cm}]$ & $242 \pm 90$ \\
\hline volume CT dose index $[\mathrm{mGy}]$ & $10.2 \pm 3.2$ \\
\hline
\end{tabular}


of this function describes the strength of resulting contrast enhancement (compare $\bullet$ Fig. 1). As $\mathrm{I}_{\mathrm{low}}$ contains less noise, postprocessing does not significantly increase image noise. All parts of the image out of the preselected range of processed HU remain completely unaffected (displayed as red lines parallel to the dashed line of the original image in 0 Fig. 1 ). To reconstruct an enhanced image $\mathrm{I}_{\mathrm{enh}}$, the unchanged image datasets $\mathrm{I}_{\text {high }}$ and processed dataset $\mathrm{I}_{\text {lowEnh }}$ are added up. Sharp details and especially the noise of image dataset $\mathrm{I}_{\text {high }}$ remain completely unaffected.

In general, this post-processing algorithm imitates a narrow window of conventional linear blending, but only affects a predefined range of $\mathrm{HU}$ values without increasing image noise. The resulting image shows increased contrast in the preselected HU range as well as the unaffected parts of the image out of the range, resulting in improved contrast and anatomical orientation compared to standard linear blending.

The algorithm is applicable to every DICOM-compatible CT image and acts as a dedicated post-processing technique in image space without having any influence on the scanning parameters.

During the post-processing procedure, the parameters center, delta and slope were defined manually to preselect the interesting sector of HU values. "Center" describes the center value and "delta" the range of influenced HU values. "Slope" defined the relative contrast enhancement ( $1=$ the image will remain unaffected, $5=$ maximum contrast enhancement).

To find the best settings of contrast enhancement of this new algorithm, two independent readers with 4 and 4.5 years of abdominal

\section{Non-linear function}

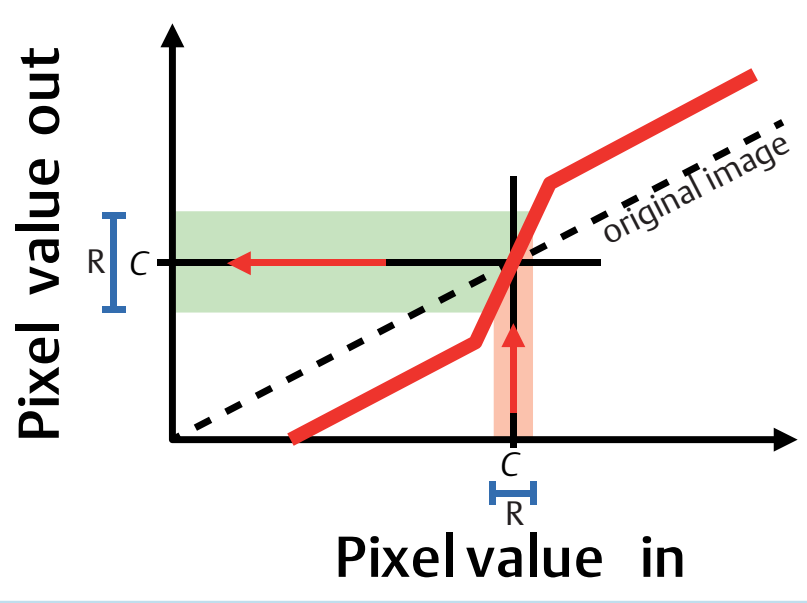

Fig. 1 Diagram of the frequency selective, non-linear blending algorithm prototype. In the data set of low frequencies, the $\mathrm{HU}$ of a preselected range (red area) are spread by the use of a non-linear function (red line). HU beyond the selected range remain unaffected (red lines parallel to the dashed line of the original image). $\mathrm{C}=$ center of preselected range of $\mathrm{HU}, \mathrm{R}=$ range of preselected $\mathrm{HU}$.

Abb. 1 Schematische Darstellung des Prototyps zur frequenzselektiven, nichtlinearen Fensterung. Im Datensatz der niedrigen Frequenzen wird ein ausgewählter Bereich (rote Fläche) an HU mittels einer nichtlinearen Funktion (rote Linie) gestreckt. Die HU außerhalb des selektierten Bereiches (rote Linien parallel zu der gestrichelten Linie des Originalbildes) bleiben unverändert. $\mathrm{C}=$ Zentrum des ausgewählten Bereichs in HU, R= Weite des ausgewählten Bereichs in HU.
CT experience (M. N. Bongers and G. Bier) independently viewed the 25 datasets of this study and adapted the center and delta values at a slope of 5 . Settings of each dataset were recorded and all image sets were computed using the averaged settings of both readers.

\section{Quantitative image analysis}

Image contrast was evaluated using region of interest (ROI) measurements of standard and post-processed images with commercially available software (Syngo.Via, Siemens Healthcare, Germany). In each dataset of equilibrium phase liver CT scans, five ROIs were placed in the left, middle and right liver vein, the liver parenchyma and in the left and right anterior/posterior major branches of the portal vein. These ROIs were propagated to the corresponding post-processed datasets. The HU and standard deviations were recorded. For each ROI, signal-to-noise ratios (SNR) were calculated by dividing the averaged $\mathrm{HU}$ by the standard deviation. Contrastto-noise ratios (CNR) were calculated as follows:

$C N R=\frac{\left(H U_{\text {vessel }}-H U_{\text {liver }}\right)}{\operatorname{StdDev}_{\text {liver }}}$

\section{Qualitative image analysis}

To assess the subjective image quality in this study, two radiologists with 4 and 4.5 years of abdominal CT experience performed an independent reading of standard $120 \mathrm{kV}$ and post-processed images. The readers were blinded to the reconstruction method and used an equidistant 5-point Likert scale to rate the overall image quality (IQ) (1: non-diagnostic IQ 2: low IQ 3: moderate IQ 4: good IQ 5: excellent IQ) and depiction of hepatic vessels (DHV) (1: no visibility, 2: poor depiction, 3: moderate depiction, 4: good depiction, 5: very good depiction). The 25 patient cases were displayed in random order. Readers were instructed to linearly blend the images freely.

\section{Statistical analysis}

All statistical analyses were performed using JMP 11.1.1 for Windows (SAS Institute, Cary, NC). Results are given as mean \pm standard deviation for parametric data or median and 25th/75th percentile for non-parametric data. Normality of the data was tested using the Shapiro-Wilk test. Due to non-normally distributed values, comparison of noise levels, CNR and SNR values from standard and post-processed images was performed using the Mann-Whitney U-test. Inter-observer agreement of subjective image analysis was determined using Cohen's kappa statistics (values of $0-0.20$, $0.21-0.40,0.41-0.60,0.61-0.80$, and $0.81-1.00$ were considered to represent slight, fair, moderate, substantial, and almost perfect agreement, respectively). A p-value of less than 0.05 was considered to be statistically significant.

\section{Results}

The assessment of the most suitable settings with respect to the center and delta of the new algorithm yielded an averaged center of $113 \pm 7 \mathrm{HU}$ and an averaged delta of $25 \pm 5 \mathrm{HU}$ at a slope of 5 . Therefore, all post-processed images with the aim of enhancing hepatic attenuation were computed with a center of $115 \mathrm{HU}$, a delta of $25 \mathrm{HU}$ and a slope of 5 . 


\section{Quantitative image analysis}

Measurements of hepatic vasculature were successfully performed in 25 equilibrium phase datasets of the liver. There was no difference in image noise in the liver veins $(p=0.43)$, portal veins $(p=0.32)$ and liver parenchyma $(p=0.64)$ between standard and post-processed images.

The CNR values of liver veins and liver parenchyma were significantly higher on post-processed images than on standard images $\left(\mathrm{CNR}_{\mathrm{NLB}} 3.6 \pm 2.94, \mathrm{CNR}_{\text {Standard }} 1.62 \pm 1.10, \mathrm{p}=0.0002\right)$ ( $\bullet$ Fig. 2 ). The averaged CNR of the portal veins and liver parenchyma was significantly higher on post-processed images than on standard images $\left(\mathrm{CNR}_{\mathrm{NLB}} 2.42 \pm 3.03, \mathrm{CNR}_{\text {Standard }} 1.31 \pm 0.85, \mathrm{p}=0.046\right)$ (० Fig. 2$)$.

Additionally, there was a significant increase in the SNR of the liver parenchyma on post-processed images than on standard images

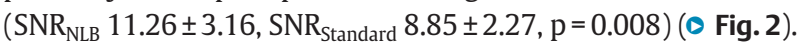

\section{Qualitative image analysis}

The inter-rater agreement for DHV and overall IQ was substantial to almost perfect (Cohens' Kappa 0.80 and 0.82 , respectively). The subjective rating of DHV and IQ was significantly higher on postprocessed images than on standard images $\left(\mathrm{DHV}_{\mathrm{NLB}}: 4\right.$ [3-4.75], $\mathrm{DHV}_{\text {Standard }}: 2$ [1.3-2.5], $\mathrm{p}=<0.0001 ; \mathrm{IQ}_{\mathrm{NLB}}: 4$ [4-4], IQ $\mathrm{Q}_{\text {Standard }}$ : $2[2-3], p=<0.0001)(0$ Fig. 3, 4).

\section{Discussion}

$\nabla$

We evaluated the potential value of a new frequency selective nonlinear blending post-processing algorithm for improving the contrast resolution of the hepatic vasculature on CT images of the liver. Our results indicate a significant increase in the subjective and objective image quality of low-contrast CT images of the liver.
In contrast-enhanced liver CT, a sufficient deposition of iodine is essential for lesion detection. There are several influencing factors which might lead to inadequate contrast enhancement, including low injection rates due to fragile veins, low contrast volumes due to impaired renal function, cardiac dysfunction, and the presence of portal hypertension. Despite best practices, a certain percentage of liver CT studies will have suboptimal contrast opacification. Therefore, techniques that improve tissue contrast are desirable. In the last decades, different approaches have been explored, including tube voltage and mAs adjustments, multiphase protocols, increased contrast agent dose, perfusion CT, monoenergetic extrapolation DECT, and nonlinear blending for SECT and DECT [3, 11 -13]. In addition, low tube voltage CT acquisition has been investigated more recently as a way to improve tissue attenuation and consequently contrast of soft tissue structures [14-16].

DECT offers the creation of low keV CT images based on monoenergetic extrapolation. At $40 \mathrm{keV}$, close to the k-edge of iodine, contrast can be significantly increased with only a minor increase in image noise $[3,5]$. Non-linear blending between image information from high and low $\mathrm{kV}$ tube in DECT also offers the possibility of increasing iodine contrast $[12,13]$.

In past decades, several non-linear blending techniques with single energy CT data have been explored. In 1985, Lehr et al. visualized whole image information with one blending setting using a histogram-based approach. Unfortunately, due to the limited grayscale of CT images, the detectability of low-contrast liver lesions was decreased [8]. A technique utilizing multiscale adaptive histogram equalization showed insufficient results in comparison with the standard window setting [17]. A technique using a reduced subset of dynamic contrast information for the simultaneous display of chest CT with lung and mediastinal window information resulted

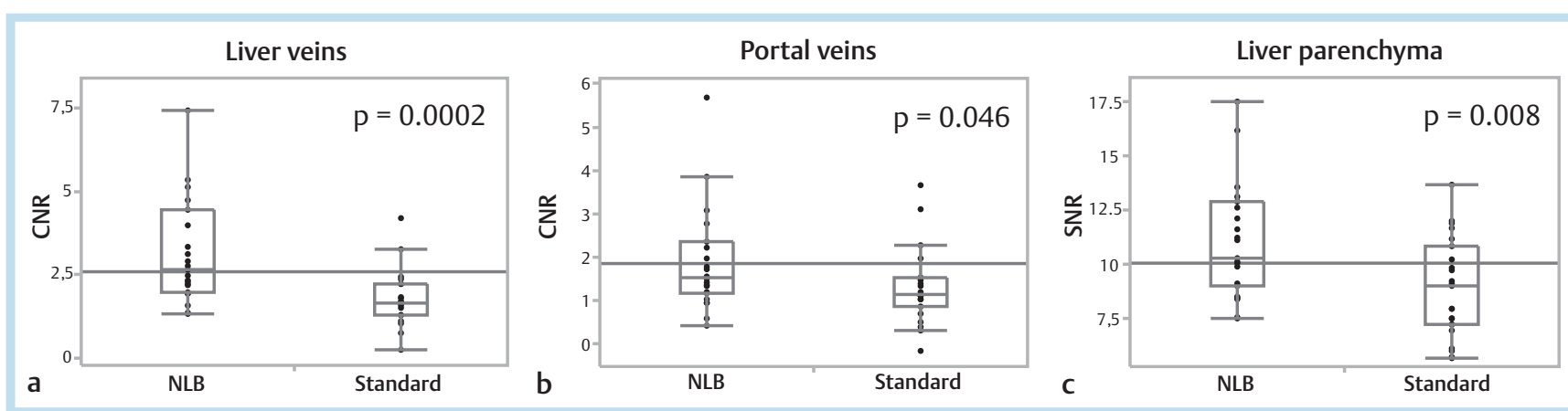

Fig. 2 Box plots of CNR values of a liver veins and $\mathbf{b}$ portal veins and $\mathbf{c}$ SNR values of the liver parenchyma of standard and post-processed images.

Abb. 2 Kastengrafik von CNR-Werten der a Lebervenen und b Pfortader sowie von c SNR-Werten des Leberparenchyms jeweils aus den Standard- und nachverarbeiteten Bildern.
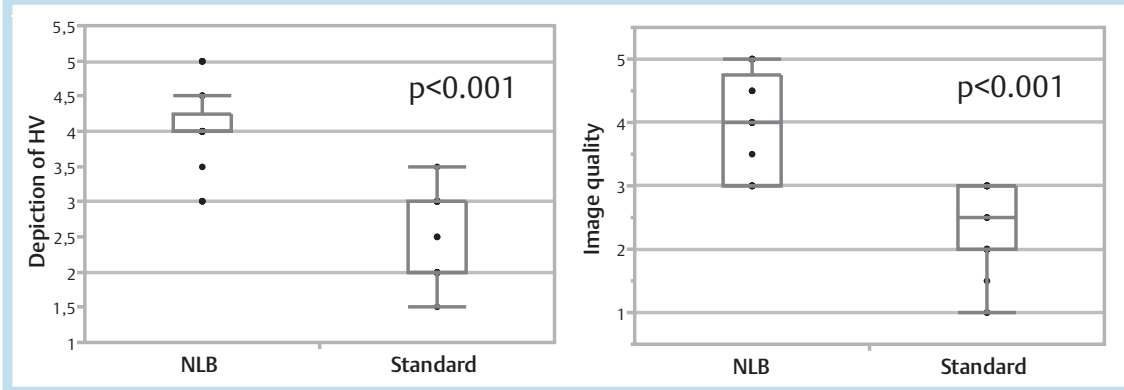

Fig. 3 Box plots of the subjective rating (Likert scale) of the depiction of the hepatic vasculature (HV) and overall image quality of standard and post-processed images.

Abb. 3 Kastengrafik der subjektiven Beurteilung (Likert-Skala) bzgl. der Erkennbarkeit der Lebergefäße und der Gesamtbildqualität von Standard und nachverarbeiteten Bildern. 

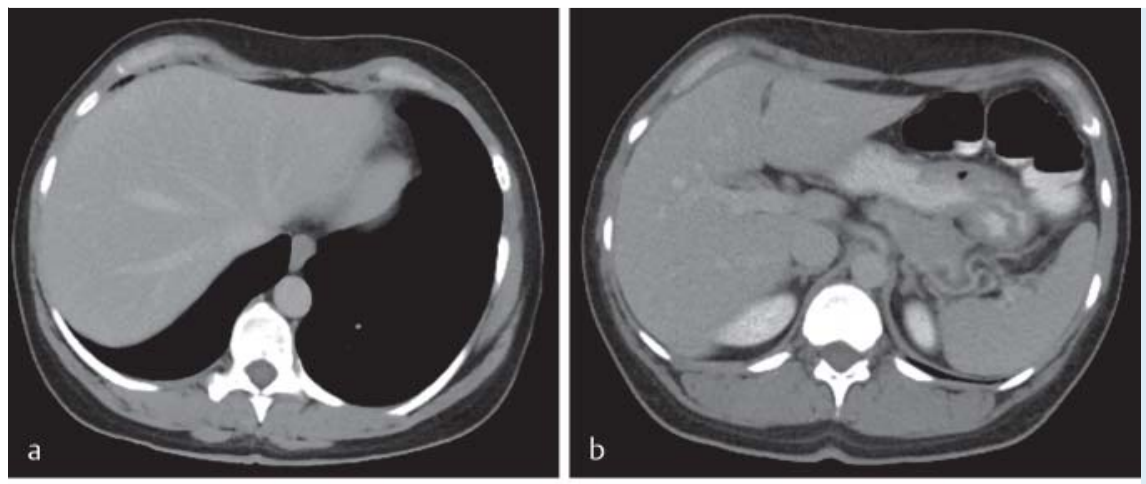

Fig. 4 Contrast-enhanced liver CT with low concentration difference between liver vasculature and liver parenchyma. $\mathbf{a}$ and $\mathbf{b}$ show standard late phase images of the liver. $\mathbf{c}$ and $\mathbf{d}$ show the same images following frequency selective non-linear blending post-processing.
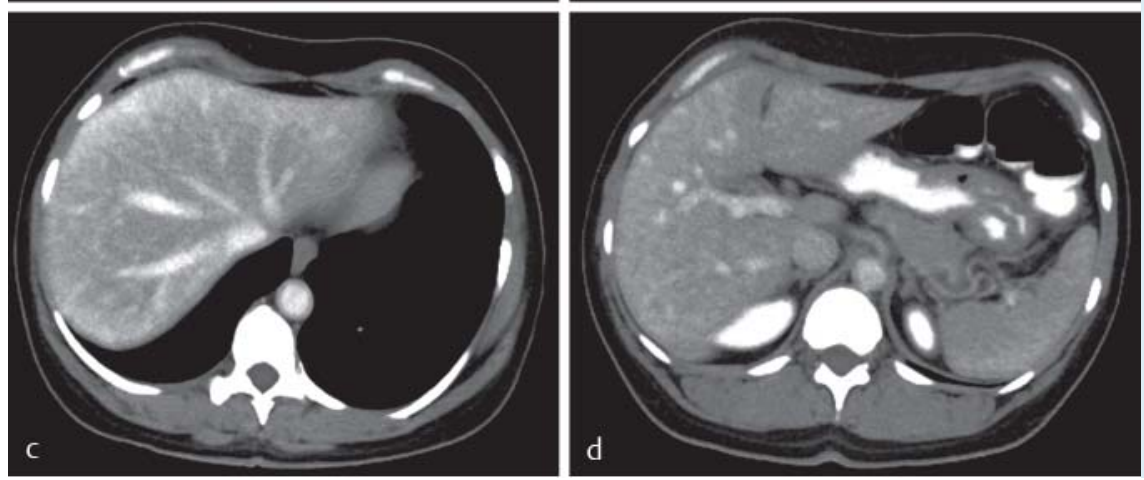

Abb. 4 Kontrastangehobenes CT der Leber mit geringem Kontrastunterschied zwischen den Lebergefäßen und dem Leberparenchym. $\mathbf{a}$ und $\mathbf{b}$ zeigen Standard-Spätphasen-Bilder der Leber. $\mathbf{c}$ und $\mathbf{d}$ zeigen die identischen Bilder nach Anwendung des Algorithmus zur frequenzselektiven nichtlinearen Fensterung.

in an improvement of operational efficiency [9]. In 1987, several empiric non-linear window pre-settings were studied to optimize the utilization of available grayscales [10]. However, none of those techniques transitioned into clinical use.

The investigated non-linear blending algorithm prototype splits the image information into two different frequency bands. High frequencies represent sharp details and noise, whereas lower frequencies show smooth content with only little noise. Hence, the algorithm highlights and spreads a defined range of the spectrum only in the low frequencies without affecting high frequencies. Afterwards, the two frequency bands compose an image with improved soft tissue contrast while noise levels remain unaffected. This procedure leads to higher contrast-to-noise ratios without an increase in image noise. Finally, this post-processing enhances the contrast of intravascular iodine at low concentrations, which otherwise may hardly be detectable on equilibrium phase CT images.

A variety of disorders, which require optimal vascular enhancement for diagnosis, affect portal and hepatic vein visualization. Oncological patients are at risk for venous thrombosis due to paraneoplastic hypercoagulation disorders and portal vein thrombosis occurs in up to $40 \%$ of patients with hepatocellular carcinoma but may be difficult to detect on arterial CT phase images only [18]. The optimal phases and delay times of liver CT exams depend on the clinical question, tumor characteristics such as the presence of increased arterialization (early enhancement), hypovascularization, fibrosis, and desmoplastic growth. In order to be able to completely answer all clinical questions related to the underlying disorder and to be also able to assess vascular complications, three or even four contrast phases may be required, resulting in increased radiation exposure. The explored post-processing technique can increase image contrast and has the potential to reduce the number of phases. Additional studies are inevitably required to assess the clinical value of this new technique.
There are limitations of this study. In this retrospective study design, patients underwent CT examination for a variety of reasons with potentially variable portosystemic hemodynamics. We did not investigate the detectability of coexisting liver lesions. Future studies with large cohorts are needed to evaluate the value of the new algorithm for detecting focal liver lesions.

In conclusion, the use of a frequency selective non-linear blending algorithm increases the contrast resolution of liver CT and can improve the visibility of the hepatic vasculature in the setting of a low contrast ratio between vessels and parenchyma.

Competing interests: Jan Fritz received institutional research funds and speaker's honorarium from Siemens Healthcare USA and is a scientific advisor of Siemens Healthcare USA and Alexion Pharamceuticals, Inc. The other authors have declared that no competing interests exist.

\section{References}

1 Vignaux 0 , Gouya H, Augui J et al. Hepatofugal portal flow in advanced liver cirrhosis with spontaneous portosystemic shunts: effects on parenchymal hepatic enhancement at dual-phase helical CT. Abdominal imaging 2002; 27: 536-540

2 Vignaux O, Legmann P, Coste J et al. Cirrhotic liver enhancement on dual-phase helical CT: comparison with noncirrhotic livers in 146 patients. American journal of roentgenology 1999; 173: 1193-1197

3 Bongers MN, Schabel C, Krauss B et al. Noise-optimized virtual monoenergetic images and iodine maps for the detection of venous thrombosis in second-generation dual-energy CT (DECT): an ex vivo phantom study. European radiology 2015; 25: $1655-1664$

4 Apfaltrer P, Sudarski S, Schneider D et al. Value of monoenergetic low$\mathrm{kV}$ dual energy CT datasets for improved image quality of CT pulmonary angiography. European journal of radiology 2014; 83: 322 - 328

5 Schabel C, Bongers M, Sedlmair M et al. Assessment of the hepatic veins in poor contrast conditions using dual energy CT: evaluation of a novel monoenergetic extrapolation software algorithm. RoFo: Fortschritte auf dem Gebiete der Rontgenstrahlen und der Nuklearmedizin 2014; 186: $591-597$ 
6 Scholtz JE, Husers K, Kaup $M$ et al. Evaluation of image quality and dose reduction of $80 \mathrm{kVp}$ neck computed tomography in patients with suspected peritonsillar abscess. Clinical radiology 2015; 70: e67-e73

7 Meyer M, Haubenreisser H, Schoepf UJ et al. Closing in on the K edge: coronary CT angiography at 100,80 , and $70 \mathrm{kV}$-initial comparison of a second- versus a third-generation dual-source CT system. Radiology 2014; 273: $373-382$

8 Lehr JL, Capek P. Histogram equalization of CT images. Radiology 1985; 154: $163-169$

9 John A, Huda W, Scalzetti EM et al. Performance of a single lookup table (LUT) for displaying chest CT images. Academic radiology 2004; 11: 609-616

10 Gomori JM, Steiner I. Non-linear CT windows. Computerized radiology: official journal of the Computerized Tomography Society 1987; 11: $21-27$

11 Sudarski S, Apfaltrer P, Nance JW Jr et al. Objective and subjective image quality of liver parenchyma and hepatic metastases with virtual monoenergetic dual-source dual-energy CT reconstructions: an analysis in patients with gastrointestinal stromal tumor. Academic radiology 2014; 21: 514-522

$12 \mathrm{Lv} P$, Liu J, Wu R et al. Use of non-linear image blending with dual-energy CT improves vascular visualization in abdominal angiography. Clinical radiology 2014; 69: e93 - e99
13 Scholtz JE, Husers K, Kaup M et al. Non-linear image blending improves visualization of head and neck primary squamous cell carcinoma compared to linear blending in dual-energy CT. Clinical radiology 2015; 70: $168-175$

14 Ippolito D, Talei Franzesi C, Fior D et al. Low kV settings CT angiography (CTA) with low dose contrast medium volume protocol in the assessment of thoracic and abdominal aorta disease: a feasibility study. The British journal of radiology 2015; 88: 20140140

15 Tang $K$, Li R, Lin J et al. The value of cerebral CT angiography with low tube voltage in detection of intracranial aneurysms. BioMed research international 2015; 2015: 876796

16 Laqmani A, Regier M, Veldhoen S et al. Improved image quality and low radiation dose with hybrid iterative reconstruction with $80 \mathrm{kV} \mathrm{CT}$ pulmonary angiography. European journal of radiology 2014; 83: $1962-$ 1969

17 Fayad LM, Jin Y, Laine AF et al. Chest CT window settings with multiscale adaptive histogram equalization: pilot study. Radiology 2002; 223: $845-852$

18 Kaufmann S, Schulze M, Spira D et al. Modern multimodality diagnosis of portal vein infiltration in hepatocellular carcinoma and expected changes during current therapies. Acta radiologica 2015; 56: 1283 1292 